\title{
Graph-Theoretic Approach to Resolving the Accessibility and Site Selection Issues in Planning and Development
}

\author{
Ayotunde Olawande Oni \\ Department of Estate Management, College of Science \& Technology; Covenant University, Ota. Nigeria \\ Tel.: +234-8023122014; E-mail: ayo.oni@covenantuniversity.edu.ng \\ Dolapo Bose Akindele \\ Department of Estate Management, Bells University of Technology, Ota. Nigeria \\ Tel.: +234-8187917006; E-mail: dolapo.akindele@bellsuniversity.edu.ng \\ Omolade Akinjare \\ Department of Estate Management, College of Science \& Technology; Covenant University, Ota. Nigeria \\ Tel.: +234-8085586781; E-mail: lade.akinjare@covenantuniversity.edu.ng
}

Doi:10.5901/mjss.2014.v5n8p11

Abstract

The basic goal of an investment in real estate is to make the highest positive net return possible, and the process of attaining this commences at the site selection stage with accessibility being of paramount consideration. Many investors, appraisers, planners and developers often base site selection and analysis of accessibility on intuition and mere physical observation of neighborhoods without scientific approach. The aim of this study is therefore to examine the application of graph-theoretic analysis in resolving the challenge of improper site selection process and accessibility issues in real estate planning development. In attaining the aim, the satellite map of the study area was derived and converted into linear graph regardless of the width, length and quality of roads. The nodal points of roads that form the network were serially numbered and translated into simple matrix of the number to obtain the accessibility indices for the ranking of access routes in the study area. The study found that the graph-theoretic approach was useful in analyzing and resolving the accessibility and site selection issues in real estate development process. The findings would provide better understanding of determination of accessibility which hitherto had been done by mere intuition by real estate appraisers and planners through the application of the approach. This is applicable to inform developers take decision relating to choice of locations by scientifically establishing the most accessibility location and thus assists in site selection. Also, it would assist the development appraisers in the ranking of several of locations along arterial routes with a view to determining sustainable physical developments.

Keywords: accessibility, appraisal, development, physical planning, real estate, site selection

\section{Introduction}

In the choice of site for real estate development, the investors usually desire the site that has potential for high positive net return. In many cases, decisions on site selection are usually based on intuition or mere subjective assumptions, especially in developing economies; this often leads to defective and abandoned projects. For viable development projects, proper site selection is largely related to accessibility with the innate assumption that must be based on scientific approaches and modern techniques.

A number of approaches have been adopted in determining the most accessible site, and by implication, selecting the site that is most likely to be viable in terms of demand for a proposed development project upon completion. In other words, the techniques assist in explaining the effects of accessibility on property values and associated with the choice of site that is most accessible since property value is a function of level of accessbility. The modern techniques include cummulative-opportunity type measure, gravity-based measure, weighted-average distance, utility-based measure, space syntax, route structure analysis, multiple regression model, hedonic model, expert system heuristics, and graph theory (see Ogunsanya, 1986; Rallis, 1988; Geertman and Ritsema, 1995; Kwan, 1998; Wyatt, 1999; Aderamo, 2003; Oni, 2009). 
It is pertinent to state that decision on site selection and accessbility in developing economies is often based on intuition and mere physical observation of the neighbourhood in which a proposed development project is to be located. Many of the real estate investments have become stalled, abandoned, or non-viable upon completion due to faulty decision on site selection. It is therefore the aim of this study to resolve the issue of accessibility and site selection decisions by applying the graph-theoretic approach, which has been widely used in road network analysis (see Cole and King, 1968; Hay, 1973; Hodder and Lee, 1982; Rallis, 1988; Wyatt, 1999; Aderamo, 2003; Marshall, 2005; Oni, 2009). The graph-theoretic approach is applied to determining the best accessible and impliedly the site that would most likely bring the highest net return in terms of location-induced viability of commercial development project.

\section{Theoretical Framework}

In this section, the theories and earlier works underpining the study are discussed; these are, location theory; transportation, complementarity and competition; accessibility and site selection analysis; and feasibility, viability and site selection.

\subsection{Location Theory}

Location theory is primarily concerned with the areal or regional pattern of distribution of productive activities, to the extent that a certain area is best suited for a particular activity but not suggesting that a given site is the best. Productive activities would derive advantages from being located within certain areas; but within the areas, there may be many sites offering such advantages. According to the theory, locations of economic activities are influenced by economies derived from large-scale operation and from proximity to complementary firms and facilities, although each is affected by internal economies of scale with varying degrees. The benefits to activities grouped in a limited geographical area include greater volume of business. Commercial activities are highly dependent upon location which determines the volume of sales and the number of sites that could be profitably occupied strictly limited and preferably located along road transport that provide good accessibility.

According to Makri and Folkesson (2007), accessibility is a slippery notion and one of the common terms that everyone uses until faced with problem of defining and measuring it. The import of this statement is that accessibility is a daily use amongst people of various backgrounds and inclinations giving way to many definitions. In transportation, accessibility refers to ease of reaching destinations. People in places that are highly accessible would reach many other activities or destinations quickly and people in inaccessible places could reach many fewer places in the same amount of time, so that nearer or less expensive places are weighted more than farther or more expensive places.

Accessibility, in general terms, describes degree to which a system is usable by as many people as possible. It is the degree of ease with which to reach certain locations from others and viewed as the ability to access functionality and possible benefit. In transportation, accessibility refers to ease of reaching destinations with people in places that are highly accessible reaching many other activities or destinations quickly, while people in inaccessible places would reach fewer places in the same amount of time (Wikipedia contributors, 2008).

Accessibility as a property of location may be grouped into general and special accessibility. General accessibility refers to nearness to rail termini, bus stations and motorways transport facilities, labour, customers and service facilities such as banks and post office; and special accessibility exists when complimentary uses are in close proximity to each other. In this case, the net economic cost of movement will be lower in terms of distance, time and convenience in addition to greater comparative advantages given greater accessibility of a location (Harvey, 1999; Balchin et al, 2000).

Handy and Niemeier (1997) identified "place accessibility" which is derived from patterns of land use. Place accessibility implies spatial distribution of potential destinations, magnitude, quality and character of activities found there. It is derived from transportation system in terms of distance, time taken, and cost of reaching each destination by different modes of transport. According to Kwan (1998), measures of place accessibility normally consist of two elements: a transportation (or resistance or impedance) element and an activity (or motivation or attraction or utility) element. The transportation element comprises the travel distance, time, or cost for one or more modes of transport, while the activity element comprises the amount and location of various activities.

A number of studies have been carried out on the significance of accessibility. Banister and Berechman (2005) stated that possible explanation for small and variable impact of urban rail investment is "ubiquitous" accessibility found in urban areas with little impact on overall accessibility and additional infrastructure where network is already well developed. However, Cervero (1998), Cervero and Wu (1998), Wegner (1995) concluded that accessibility increasingly shapes metropolitan location decisions and it is people's desire for location advantages and real estate developers' 
awareness of those desires that give rise to urban form. They stated further that under conditions of ubiquitous accessibility, monumental transport improvements have little effect on location.

\subsection{Transportation, Complementarity and Competition}

In explaining patterns of property values and urban land use, Lean and Goodall (1977), Harvey (2000), and Sirota (2004) opined that the centre of an urban area is the position of greatest accessibility where transport routes and systems converge. Competition between firms whose revenue is high when in such a position will force up rents and land values above those in the remainder of the urban area. Firms will compete to locate in the centre to take advantage of complementarity, which to large extent, is a function of accessibility. The larger the urban areas the more distinct will the clusters of complementary uses become. For instance, the office centre will separate from the shopping centre.

Similarly, the higher the degree of accessibility and complementarity, the larger the urban area and the higher the land values in the centre are likely to be. As accessibility decreases from the centre it is expected that the value of commercial property will decrease, that is, where main and secondary roads are placed will be major determinant in the location of the commercial uses. Commercial uses would normally attract land away from industrial uses such that the general pattern would be the highest land values for commercial uses, the next highest for industrial uses, and the lowest for residential accommodation. Complementarity or incompatibility of properties may be an important factor that determines land values in an urban area. If land in a given part of a town is put into complementary uses, this will likely enhance the land values whereas if they are incompatible with each other it may lower the land values. Developments in transport routes or systems may lead to changes in land values in an urban area. By such developments, some land values may rise as accessibility increases while others may fall as incompatible uses move nearby causing general pattern of land uses and values in the urban areas.

\subsection{Accessibility and Site Selection Analysis}

According to Muraco (1972), accessibility is associated with geographic notion of situation and relating to the elements of spatial relationships, interaction, and connectivity. In the study, accessibility index was derived through three analytical phases, which included the use of finite graph theory to define geometric structure of the study network. Edges were defined by major thoroughfares intersecting to provide vertices. It established that in dealing with intra-urban road network, not all roadways may be included but major thoroughfares that reflect relevant linkages of the transport network. This involves an analysis of the incidence structure for the networks to provide initial set of accessibility measures and binary connectivity matrix prepared from where Shimbel index showing measure of nodal accessibility is obtained. In this case, the element of Shimbel distance matrix indicates the linkages to other nodes in the system, and nodes that are characterized by large number of linkages to other nodes may be assumed to be most connected than those having only few linkages. Similarly, in measuring accessibility, the number of links in the shortest path from a particular node to its remote node is determined; the lower the associated number of a node, the higher the accessibility level of that node to the system.

Alternative method of configuration analysis is the space syntax adopted in Marshall (2005). The study recognized that 'link' elements in a layout may have significant spatial presence. In urban structure, land use zones and roads may be represented separately as nodes and links but in traditional urban network streets are significant spatial entities. The approach used axial lines, which are the longest lines of sight and access through open space; and convex spaces which is the maximal convex polygon that could be drawn in open space. Each of the elements is defined by geometry of the local boundary in different regions of the space map. The translation of such map into a complete set of intersecting axial lines or overlapping convex spaces produces the axial map or overlapping convex map respectively. The resultant axial map thus allows a network amenable to graph mathematics to be carried out in a well-defined manner and makes possible the analysis of the urban networks. The basic method of analysis boils down to identifying axial lines (which have some correspondence to lines of movement, or physical routes) and transforming the lines into the vertices of a graph while the axial intersections become the edges. This transformation creates a graph structure underlying network structure and the resulting graph is analyzed using the conventional graph-theoretic measures.

In addition to the concepts of connectivity, space syntax makes use of concept of depth, which is a measure of network 'distance' (i.e. steps of adjacency) between network components. The depth of any axial line may be more related to continuity of roads and paths as routes than on their inter-visibility across space. This has opened up the question of what might be the most appropriate elemental units for representing the "active ingredients" of movement structure. A transport network can be considered as a topologic graph with three parameters from which quantitative 
measurements may be computed as basis for objective description, comparison and evaluation of the network. The parameters include a number of separate non-connecting sub-graphs in the network represented by $G$, the number of links (or edges) in the network (E) and the number of nodes (or vertices) in the network (V). A number of topological approaches of road network structure measure the connectivity of a road network. There are four of such measures, namely, Beta Index, Chromatic Number, Alpha Index, and Gamma Index. They are defined on the basis of three parameters of network topology, that is, the number of edges (road segments) (e); the number of vertices (nodes) $(v)$ including road intersections, travel origins and destinations; and the number of maximally connected components $(g)$ (Cole and King, 1968; Hay, 1973; Hodder and Lee, 1982; Rallis, 1988; Batty, 1999).

Different measures often show different approaches to accessibility indices of locations. Pirie (1979) and Kwan (1998) focused on individual accessibility, while many others (for instance, Geertman and Ritsema van Eck, 1995; Song, 1996; Handy and Niemeier, 1997) more or less focused on place accessibility. Handy and Niemeier (1997) claimed that the best approach to measuring accessibility does not exist and that different situations and purposes demand different approaches. They identified four inter-related issues to be resolved, namely the degree and type of disaggregation, definition of origins and destinations, measurement of travel impedance and measurement of attractiveness.

The route network pattern has been analyzed in many studies using variety of techniques, which include urban morphology (Cozen, 1969; Whitehand, 1981; Moudon, 1997), fractal analysis (Batty and Longley, 1994), cellular automata (Batty, 1997), traffic pattern analyses (Vaughan, 1987; Taylor, 2000), and graph theoretic approach (Muraco, 1972). The graph theory is a branch of combinational topology and versatile language that allows basic structure of transportation networks to be disentangled (Lowe and Moryada, 1975). A graph is a set of discrete points joined by lines respectively referred to as vertices and edges; and in a graph, it is the topological arrangement between elements that is important rather than the absolute geometry or scale of the elements represented (Marshall, 2005).

Xie and Levinson (2006) identified typology as an arrangement and connectivity of nodes and links of a network long-standing interest in measuring spatial structure of road networks that is driven by inherent impact of network structure on performance of transportation systems with subsequent effects on land use and urban form. Some earlier works (Garrison and Marble, 1960; Kansky, 1963; Harggett and Chorley, 1969) exclusively focused on topologic measures adopting graph-theoretic network analysis but were constrained by limited data, computational power, and modeling techniques. Subsequent work (for example, Vaughan, 1987) explored the effects of various geometric network structures on traffic flows and travel pattern and with widespread availability of travel demand models.

There are two kinds of analysis that are based on graph theory; these are conventional transport network analysis and syntax - a method of analyzing urban spatial structure. In accessibility by transport network analysis, a transport network is represented conventionally as a graph, the links in the network becomes edges in the graph and the nodes (junctions) are vertices. It is therefore possible to use various graph-theoretic indicators to analyze network structure and capture properties such as connectivity and determine the accessibility indices. In general, graph theoretic analysis uses vertices to represent the primary elements and edges to represent the primary elements, and edges to represent the relationships between those elements. In the case of transport network, the primary elements could be the nodes which are joined by lines of movement, joining at nodes (junctions) and both are represented by a graph in which the nodal points are vertices and line of movements are edges (see Thompson, 1948; Berge, 1958; Nystuen and Dacey, 1961; Hagget and Chorley, 1969; March and Steadman, 1971; Kruger, 1979; Hillier and Hanson, 1984; and Broadbent, 1988; Thomson and Richardson, 1999; Mackaness and Edwards, 2002; Zang and Lund University, 2004).

Ingram (1971), Handy and Niemeier (1997), and Harvey (2000) pointed out that place accessibility is derived from patterns of land use; that is, the spatial distribution of potential destinations and the magnitude, quality and character of activities found there. It is derived from the transportation system, namely the distance, the time taken and the cost of reaching each destination by different modes of transport. Measures of place accessibility consist of two elements: a transportation (or resistance or impedance) element and an activity (or motivation or attraction or utility) element. The transportation element comprises the travel distance, time, or cost for one or more modes of transport, while the activity element comprises the amount and location of various activities (Handy and Niemeier, 1997; Kwan, 1998).

Place accessibility may be operationalized in several ways depending on the issue at hand, the area of the application, means and limitations concerning resources, and feasible data. This is by integral measures comprising cumulative-opportunity measures, gravity-type measures, and utility-based measures. Irrespective of what kind of integral measure chosen, the measure is calibrated to reflect how individuals and households perceive the travel and destination choices available to them. Distance approach is accessibility measure involving counting the distance from one location to different opportunities and measured as average distance, weighted area distance, or distance to the closest opportunity. The estimation of these distances is performed in several ways, from simple straight-line distances to more complicated impedance formulations (Ingram, 1971; Handy and Niemeier, 1997). The simple straight-line distance 
approach involves counting of distance from one location, for instance, the central business district, to a given destination, and the closer the destination to the CBD the higher the accessibility (Song, 1996). Measuring accessibility by average distance estimates either the average distance to one destination from all departure points in the area, or the opposite, the average distance to all destinations from one departure point or zone. Weighted average distance makes up for this drawback by including the attractiveness of the destination while application that is somewhat more comprehensive is the "shortest distance" measure. The shortest distance is determined by household mean-expenditure and the mean for weighted distances divided by total expenditure on goods and services (Guy, 1983). Another approach is the gravity-based measures, which is derived from denominator of the gravity model for trip distribution. The gravitybased measures are based on law of physics and arguments from statistical theory used to support an exponential form of the model. The measures are obtained by weighting opportunities in an area and such measure indicates their attraction and discounting them by an impedance measure (Geertman and Ritsema, 1995; Handy and Niemeier, 1997; Kwan, 1998).

From these, a number of approaches including the graph-theoretic measure have been identified; however, the graph-theoretic approach has been considered in this study due to its simplicity and possible ease of understanding of its computation by real estate investors and appraisers in developing economies and elsewhere for its application to resolving site selection and accessibility issues, especially in feasibility and viability appraisal of real estate development. The graph-theoretic approach was used in this study to define road network on basis of weighted and non-weighted, static and geometric criteria. The theory is applicable to this study for its simplicity yet analytical features that enable conversion of qualitative data to quantitative measures.

\subsection{Feasibility, Viability and Site Selection}

As part of feasibility and viability appraisal, site that enables viable real estate development is selected on the basis of measuring the needs of a new project against the merits of the level of accessibility of its potential locations. The site selection process includes detailed evaluation of project needs which are then measured against the merits of potential locations. The process typically includes selecting and evaluating communities, real estate site analysis and acquisition (Berman and Evans, 2006)

According to the U.S. General Services Administration, site selection considerations begin early in the capital development process and play significant role in pre-planning discussions. The process includes defining project criteria, evaluating communities, creating short list of communities based upon project criteria, identifying real estate sites within each finalist community, and real estate analysis. Response to the question of "what is the most important three things in retail?" is: location, location and location. Location is very important element for customer to prefer a store. Location is also competition advantage which is not easy to simulate; and for a retail enterprise, location may result as success or failure. A good location is related with target market, rivals and costs, features of the trade area surrounding the location, number of families within and near the area and ease at which customers from other areas get to the location (Hand, et al 1979; Aydin, 2005).

Proper places give chance to easy transportation, attracts lots of customers, and change customers' shopping and buying concepts. Among the retail stores which sells almost the same goods, the ones in different locations, may have big portion on market share and profitability. Retailers are therefore careful while choosing store location because location is important to exploit development survivable competition advantage. Retailers can easily change prices, services and good diversity, and determine the values of different trading zones, and then type of desirable location is determined, general location is chosen, and a special site is selected (see Levy and Weitz, 2001; Aydin, 2005; Berman and Evans, 2006).

In the opinion of Grasskamp (1970), real estate feasibility analysis divides into three problems; which are investigating alternative uses where there is a pre-determined site; investigating alternative sites where there is a predetermined use; and investigating alternative investment opportunities where there are pre-determined funds. In agreement with this, Kolbe and Greer (2009) added the steps involved in feasibility appraisal of real estate development. The steps are assessing the physical and legal aspects of the site; estimating demand for the proposed real estate services, including issues of transportation, accessibility, and services; analyzing the competitive space including the present and future competitive sites to estimate the degree of pressure on rents and likely vacancy rates; estimating the cost of construction; estimating the cost of financing including consideration for possible combinations of equity and debt financing packages; and estimating the rate at which the units would be rented or sold; developing schedule of cash inflows and outflows; and evaluating the anticipated cash flows for adequacy, given the investor's minimum acceptable rate of return and degree of risk vis-à-vis the market rate of return. 
From this, every step in the feasibility appraisal of real estate projects relates to the issue of accessibility. Accessibility plays important part in the number of people that require amenities and basic space requirement; competition for a particular site in order to estimate the degree of pressure on rents and likely vacancy rates. In addition, accessibility issue greatly determines the cash flows, and the rate at which each unit of real estate project would let or sell in a transaction involving willing and able purchaser (owner) and vendor (tenant) none of whom is under pressure to participate in the transaction. It therefore implies that site selection has great impact on feasibility and viability of real estate project and accessibility greatly influences the nature and type of particular site, with site having greater accessibility advantage outplaying others with less advantage.

The aim of this study is therefore to determine the appropriateness of the graph-theoretic approach, which has been tested in studies on road network analysis in Nigeria (see Oni, 2007; Oni, 2008; and Oni, 2009) to the analysis of accessibility within a community and in relation to viability of real estate development project vis-à-vis site selection. This is with a view to resolving the accessibility and site selection issues in real estate development process. In doing so, Ikeja city was adopted for the study. The study area is the capital of Lagos State and a large component of the Lagos metropolis, and one of the thirty-six states in Nigeria. It is located at 6 ${ }^{\circ} 34^{\prime} 60^{\prime \prime} \mathrm{N}, 3^{\circ} 19^{\prime} 59^{\prime \prime} \mathrm{E}$ along the West African coast. There are ninety (90) major roads in the study area out of which thirty-seven are arterial. From the thirty-seven arterial roads, twenty traverse the commercial axes while others serve institutional, industrial, and residential neighbourhoods. This study covers only the major roads serving the commercial axis and inner areas while excluding the inter-city roads that form rings around the study area having a network of twenty-one (21) arterial roads; twenty of the roads traverse the commercial axes of the study area while one serves government establishments.

\section{Research Methodology}

Using the graph-theoretic technique, the road map of the study area showing major transport routes was converted to linear graph regardless of the width, quality, and standard of the roads. The points at which two or more roads connect are numbered serially from 1 until the entire nodal points in the network has been assigned with numbers. From this, accessibility matrix was prepared to determine the degree of accessibility of each node within the road network, and each node was rated according to the level of accessibility using the Shimbel index. The Shimbel index matrix summarizes the number of edges required to connect every node or vertex with the others in the network through the shortest path. The nodal points with the lowest index thus revealed the most accessible location in the study area.

In this case, Fig. 1 shows the satellite map of the study area and indicates the total number of arterial roads traversing the neighbourhoods.

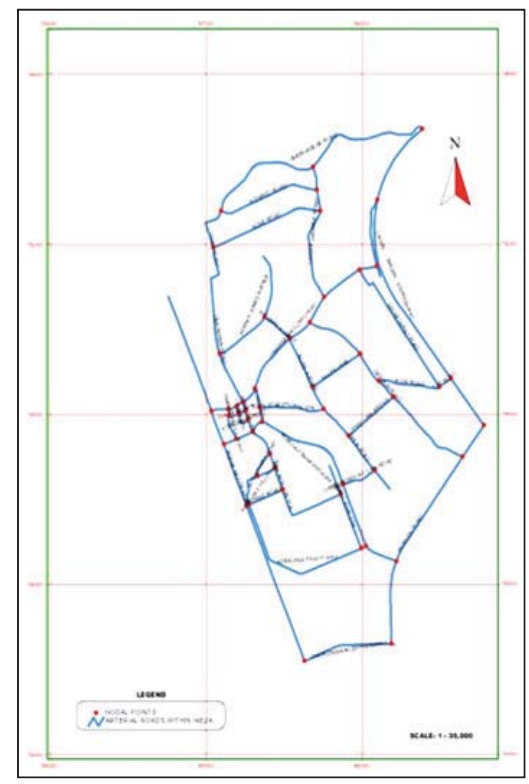

Fig. 1: Satellite Map Showing the Road Network of Ikeja, the Study Area

Source: Lagos State Planning Information Centre, Ikeja 
The satellite map in Fig. 1 was coverted to graph of the network by linking nodal points through the straight and shortest path possible. This was made possible by placing transparent sheet on the satellite map and drawing straight lines to connect nodes (where two or more roads meet) to form edges.

Furthermore, the relative accessibility indices of the roads were determined. In this case, Fig. 1 was converted to linear graph regardless of the width, quality, and standard of the roads as shown in Fig 2.

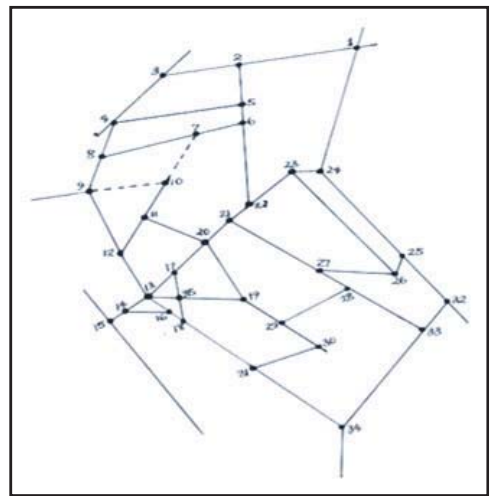

Fig. 2: Graph of Arterial Road Network in Ikeja

As shown in Fig. 2, thirty-five (35) nodal points are revealed within the study area. Thus, the accessibility matrix was prepared to form a 35-by-35 column matrix corresponding to the number of lines that connect the nodal points to form the links, which are were numbered from 1 to 35 in relation to the number of links. The number of links between a nodal point and every other having direct link to it was indicated in each box to obtain the accessibility index; this represents the level of accessibility of the particular road axis. The process was repeated for every road until the entire networks was covered. The totals indicated in the accessibility index column thus represent the ranks to determine the relative accessibility as shown in Table 1. However, in operationalizing the accessibility and connectivity indices for thirty-five nodal points in the road network, all nodal points were weighted over the twenty arterial roads identified to obtain the levels of accessibility and connectivity in the network using Eqn. 1 formulated in Oni (2007) applied in Oni $(2008,2009)$

$$
a_{,}\left(c_{i}=\frac{n p_{14}+n p_{\mathrm{z}}}{5_{1} m p_{1}+m p_{2}} \times \frac{m p_{1}}{m p_{2}}\right.
$$

where,

$\mathrm{a}(\mathrm{c}) \mathrm{i}=$ accessibility or connectivity index;

$n p_{1 i}=$ accessibility or connectivity index of lower nodal point;

$\mathrm{np}_{2 \mathrm{i}}=$ accessibility or connectivity index of higher nodal point;

$\mathrm{rnp}_{1}=$ rank for lower nodal point;

$\mathrm{rnp}_{2}=$ rank for higher nodal point;

\section{Findings and Discussion}

The result of analysis of the level of accessibility of the arterial roads is shown in Table 1 (see APPENDIX). From the analysis, nodal point 21 with has the least accessibility index of 106 (Obafemi Awolowo Way/Oregun Road) is the most accessible; followed by node 20 (Obafemi Awolowo Way/Allen Avenue) with index 107; and node 22 (Obafemi Awolowo Way/Lateef Jakande Road) with 114. The least accessible nodal point is 15 (end of Obafemi Awolowo Way with Lagos/Abeokuta Expressway) that has accessibility index of 178; followed by Iseri/Agege Road by Berger Area (nodal point 3 with index of 167). This showed that all the nodal points with low accessibility indices are located along Obafemi Awolowo Way, thus showing that the road is the most important delivering much of accessibility in the road network of the study area. This thus implies that investor, developer, and appraiser would consider the road for commercial real estate development.

However, thirty-five (35) nodal points were identified within the network of twenty (20) arterial roads in the study area, thus the necessity for further analysis using Eqn. 1. The equation was adopted to determine the relative weighted accessibility indices of the twenty arterial roads in relation to thirty-five nodal points in the study area summarized in Table 2. 
Table 2: Weighted Accessibility Indices of Arterial Roads in Ikeja

\begin{tabular}{clcc}
\hline S/N & Arterial Road & Weighted Index & Rank \\
\hline 1 & Obafemi Awolowo Way & 0.10 & 1 \\
\hline 2 & Toyin Street & 0.55 & 2 \\
\hline 3 & Bank Anthony Way & 0.57 & 3 \\
\hline 4 & Lateef Jakande Road & 0.58 & 4 \\
\hline 5 & Isheri-Agege Road & 0.64 & 5 \\
\hline 6 & Ogba Road & 0.64 & 5 \\
\hline 7 & Oregun Road & 0.65 & 7 \\
\hline 8 & Opebi Linkroad & 0.69 & 8 \\
\hline 9 & Simbiat Abiola Way & 0.72 & 9 \\
\hline 10 & Aromire Avenue & 0.73 & 10 \\
\hline 11 & Ikosi Road & 0.73 & 10 \\
\hline 12 & Olowu Street & 0.73 & 10 \\
\hline 13 & WEMPCO Road & 0.73 & 10 \\
\hline 14 & Adeniyi Jones Avenue & 0.74 & 14 \\
\hline 15 & Allen Avenue & 0.74 & 14 \\
\hline 16 & Kodesho Street & 0.74 & 14 \\
\hline 17 & Oba Akran Avenue & 0.74 & 14 \\
\hline 18 & Opebi Road & 0.74 & 14 \\
\hline 19 & Opebi/Bank-Anthony Way & 0.74 & 14 \\
\hline 20 & ACME Road & 0.75 & 20
\end{tabular}

From Table 2, the analysis accessibility of the major arterial roads in the study area using the weighted relative accessibility indices showed the importance of different roads in terms of their relative accessibility. The road with the lowest accessibility index is considered to be the most accessible. Therefore, the weighted relative accessibility index further indicated Obafemi Awolowo Way as the most accessible, followed by Toyin Street and Bank-Anthony Way, while the least accessible is ACME Road. Also, Isheri-Agege and Ogba Roads; Aromire Avenue, Ikosi Road, Olowu Street, and WEMPCO Road; Adeniyi Jones Avenue, Allen Avenue, Kodesho Street, Oba Akran Avenue, Opebi Road, and Opebi/Bank-Anthony Way have equal degrees of accessibility in the arterial road network in the study area. This finding confirms the actual situation in the study area and probably explains reasons for high concentration of pedestrian and vehicular movements and business activities along the routes with high concentration of converted and purpose-built commercial properties to take advantage of the accessibility levels. Furthermore, the importance of this finding is that the ordering of the arterial roads might be a guide to property developers who consider accessibility as major factor of physical criteria in determining the feasibility and viability of a development project to make choice out of the alternative location in the study area. Also, the study has demonstrated the relevance and application of the graph-theoretic approach in determining the level of accessibility in a community; thus assisting real estate developers, appraisers, and investors in resolving accessibility and site selection issues, which are often determined by mere intuition.

\section{Concluding Remarks}

The study has demonstrated the application of the graph-theoretic approach, which is a useful tool road network analysis, to resolving the accessibility and site selection issues in real estate development project. The approach has been tested in University community and larger metropolitan area of Ikeja in Lagos State, with the result that it may be applied in even larger community for ordering various levels of accessibility and ranking of locations for efficient physical planning. This would assist in site selections for physical developments which entirely depend great on accessibility. There is need to adopt the approach giving great opportunity for further research. It is hoped that the findings will go a long way in assisting developers, real estate appraisers, and investors in resolving site selection and accessibility issue in feasibility and viability appraisals with some level of confidence. The graph-theoretic approach would assist in adopting more analytical approach to accessibility and site selection efforts which had hitherto been determined by intuition, thus ensuring effective and sustainable physical development. 


\section{References}

Aderamo, A. J. (2003). A Graph Theoretic Analysis of Intra-Urban Road Network in Ilorin, Nigeria. Research for Development - The Journal of Nigerian Institute of Social and Economic Research, 17 (1) and (2); 18 (1) and (2) Dec. 2003, 221 - 240

Aydin, K. (2005). Perakende Yönetimin Temelleri, 1. Basım, Nobel Yayın Dağıtım, Ankara, P.103-104-157-158.

Balchin, P. N.; Kieve, J. L.; and Bull, G. H. (2000). Urban Economics - A Global Perspective. New York: Palgrave Publishers, $1^{\text {st }}$ Ed.

Banister, D. and J. Berechman (2005). Transport Investment and Economic Development. London: UCL Press.

Batty, M. (1997). A Research Programme for Urban Morphology in Environment and Planning B: Planning and Design, 26, 475 - 476.

Batty, M. (1999). A Research Programme for Urban Morphology in Environment and Planning B: Planning and Design, 26, 475 - 76.

Batty, M., and P. Longey (1994). Fractal Cities: A Geometry of Form and Function. London and San Diego: Academic Press.

Berge, C. (1958). The Theory of Graphs and its Applications. London: Methuen

Berman, B. and J. R. Evans (2006). Retail Management, 8th edition, New Jersey: Prentice Hall; 318 - 349.

Broadbent, G. (1988). Design in Architecture. London: David Fulton

Cervero, R. (1998). The Transit Metropolis: A Global Inquiry. Washington, D. C.: Island Press.

Cervero, R. and K. L. Wu (1998). Sub-centering and Commuting: Evidence from the San Francisco Bay Area. Urban Studies, 35, 10591076.

Cole, J. P and King, C.A.M. (1968). Quantitative Geography Techniques and Theories in Geography. London: John Wiley \& Sons Ltd.

Cozen, M. R. G. (1969). Alnwick, Northumberland: A Study in Town Plan Analysis. Publication No. 27. London: Institute of British Geographers

Garrison, W. L. and D. F. Marble (1960). Connectivity of the Inter-state Highway System. Paper of the Regional Science Association. 6 , $121-137$

Geertman, S. C. M and V. E. J. R. Ritsema (1995). GIS and Models of Accessibility Potential: An Application in Planning. International Journal of Geographical Information Systems, 9 (1), 67 - 80.

Grasskamp, J. A. (1970). A Guide to Feasibility Analysis. Chicago: Society of Real Estate Appraisers, 4

Guy, C. M. (1983). The Assessment of Access to Local Shopping Opportunities: A Comparison of Accessibility Measures. Environment and Planning B, 10: 219 - 238.

Haggett, P. and J. C. Chorley (1969). Network Analysis in Geography. London: Butler \& Tanner Ltd., 261-318.

Hand, H. H.; H. H. Dunkelberg; J. S. Unkelberg; and W. P. Sineath (1979). Economic Feasibility Analysis for Retail Location. Journal of Small Business Management, July, 1979; Vol. 17, Issue 3; 29.

Handy, S. L. and D. A. Niemeier (1997). Measuring Accessibility: An Exploration of Issues and Alternatives. Environment and Planning, $29,1175-1194$.

Harvey, J. (2000). Urban Land Economics. $5^{\text {th }}$ Ed. New York: Palgrave.

Hay, A. (1973). Transport for the Space Economy. A Geographical Study. London: The Macmillan Press Limited.

Hillier, B. and J. Hanson (1984). The Social Logic of Space. Cambridge: Cambridge University Press

Hodder, B. W. and R. Lee (1982). Economic Geography. London: Methuen \& Co. Limited.

Ingram, D. R. (1971). The Concept of Accessibility: A Search for an Operational Form. Regional Studies, 5, 101 - 107.

Kansky, K. J. (1963) Structure of Transportation Networks: Relationship between Network Geometry and Regional Characteristics. University of Chicago Department of Geography Research Paper No. 84. Chicago: University of Chicago.

Kolbe, P. T. and G. E. Greer (2009).Investment Analysis for Real Estate Decisions. $7^{\text {th }}$ Ed.: Chicago, IL: Dearborn Real Estate Education

Kruger, M. T. J. (1979). An Approach to Built-form Connectivity at an Urban Scale: System Description and its Representation. Environment and Planning B; Planning and Design, 6, 67 - 88.

Kwan, M. P. (1998). Space-Time and Integral Measures of Industrial Accessibility: A Comparative Analysis Using a Point-based Framework. Geographical Analysis 30, 3, $199-216$.

Lean, W. and B. Goodall (1977). Aspects of Land Economics. London: The Estate Gazette Ltd., 135 - 141.

Levy, N. and Weitz, T. (2001). Retallıng Management, 4th edition, McGraw-Hill, New York, 259.

Lowe, J. C. and S. Moryada (1975). The Geography of Movement. Buston: Houghton Mifflin Co.

Mackaness, W. and E. Edwards (2002). The Importance of Modelling Pattern and Structure in Automated Map Generalisation. Joint ISPRS/ICA workshop on Multi-Scale Representations of Spatial Data, Ottawa, Canada, 7- 8 July 2002

Makri, M. C., and C. Folkesson (2007). Accessibility Measures for Analyses of Land Use and Travelling with Geographical Information Systems in http://www.tft.lth.se/ kfbkonf/ 4 Makrifolkesson.pdf

March, L. and J. P. Steadman (1971). The Geometry of Environment: An Introduction to Spatial Organization in Design. London: RIBA Publications.

Marshall, S. (2005). Street and Patterns. New York: Spon Press.

Moudon, A. V. (1997). Urban Morphology as an Emerging Interdisciplinary Field. Urban Morphology, 1, 3 - 10.

Muraco, W. A. (1972). Intra-urban Accessibility: A Quantitative Analysis Use of Graph Theoretic Method. Economic Geography. 48, 388 -405 .

Nystuen, J. C. and M. F. Dacey (1961). A Graph Theory Interpretation of Nodal Regions. Paper and Proceedings Regional Science 7, 29 -42 .

Ogunsanya, A. A. (1986). Graph Theory in Intra-urban Traffic Flow Estimation. Geo-Journal, 12334 - 336

Oni, A. O. (2007). Analysis of Accessibility and Connectivity of Ikeja Arterial Roads. Paper Presented at the 1st National Conference 
organized by Department of Estate Management, Yaba College of Technology, Lagos, Held on $25^{\text {th }}$ to $27^{\text {th }}$ day of September 2007.

Oni, A. O. (2008). Graph-Theoretic Analysis of Intra-Community Road Network Pattern: Case Study of Covenant University, Ota, Nigeria. The Lagos Journal of Environmental Studies. 6 (1), 24-37.

Oni, A. O. (2009). Arterial Road Network and Commercial Property Values in Ikeja, Nigeria. Unpublished Ph.D. Thesis; Department of Estate Management, Covenant University, Ota, Nigeria.

Pirie, G. H. (1979). Measuring Accessibility: A Review and Proposal. Environment and Planning, A; 11, 299 - 312.

Rallis, T. (1988). City Transport in Developed and Developing Countries. London: The Macmillan Press Limited.

Sirota, D. (2004). Essentials of Real Estate Investment. $7^{\text {th }}$ Ed. Chicago, IL: Dearborn Real Estate Education

Song, S. (1996). Some Tests of Alternative Accessibility Measures: A Population Density Approach. Land Economics, 72 (4), 474 - 482.

Taylor, M. A. P. (2000). Using Network Reliability Concepts for Traffic Calming: Permeability, Approachability and Tortuosity in Network Design. In Bell, M. G. H. and Cassir, C (eds.) Reliability of Transport Networks. Baldock: Research Studies Press Limited.

Thompson, D. W. (1948). On Growth and Form. Cambridge: University Press.

Thomson, R. C. and D. E. Richardson (1999). A Graph Theory Approach to Road Network Generalisation. In Proceeding of the 17th International Cartographic Conference, 1871-1880.

Vaughan, R. (1987). Urban Spatial Patterns. London: Pion

Wegner, M. (1995). Accessibility and Development Impacts In Banister, D. (1995). Transport and Urban Development. London: E \& FN, $158-159$.

Whitehand, J. W. R. (ed.) (1981). The Urban Landscape: Historical Development and Management: Papers by M. R. G. Conzen. IBG Special Publication, No. 13. London: Academic Press.

Wikipedia Contributors (2008). Arterial Roads in Wikipedia, The Free Encyclopedia, http://en.wikipedia.org/w/index.php?title=Arterial road\&oldid= 212832640 (accessed May 30, 2008)

Wyatt, $\bar{P}$. (1999). Geographical Analysis in Property Valuation. Research Report, Royal Institution of Chartered Surveyors, London.

Xie, F. and D. Levinson (2006). Measuring the Structure of Road Networks in http://rational.ce.umn.edu/Papers /Topology.pdf

Zhang, Q. and Lund University, GIS Centre, Sweden (2004). Modeling Structure and Patterns in Road Network Generalization. Paper Presented at ICA Workshop on Generalization and Multiple Representation, held in Leicester, 20-21 August, 2004.

\section{Appendix I}

Table 1: Accessibility Indices of Arterial Roads in Ikeja Metropolis

\begin{tabular}{|c|c|c|c|c|c|c|c|c|c|c|c|c|c|c|c|c|c|c|c|c|c|c|c|c|c|c|c|c|c|c|c|c|c|c|c|c|c|}
\hline NP & 1 & 2 & 3 & 4 & 5 & 6 & 7 & 8 & 9 & 10 & 11 & 12 & 13 & 14 & 15 & 16 & 17 & 18 & 19 & 20 & 21 & 22 & 23 & 24 & 25 & 26 & 27 & 28 & 29 & 30 & 31 & 32 & 33 & 34 & 35 & $\mathrm{Al}$ & Rank \\
\hline 1 & - & 1 & 2 & 3 & 2 & 3 & 4 & 4 & 5 & 5 & 6 & 6 & 7 & 8 & 9 & 8 & 6 & 7 & 6 & 5 & 4 & 3 & 2 & 1 & 2 & 3 & 4 & 5 & 6 & 7 & 6 & 3 & 4 & 5 & 7 & 159 & 33 \\
\hline 2 & 1 & - & 1 & 2 & 1 & 2 & 3 & 3 & 4 & 4 & 5 & 5 & 6 & 7 & 8 & 7 & 6 & 8 & 6 & 5 & 4 & 3 & 3 & 2 & 3 & 4 & 5 & 6 & 7 & 8 & 7 & 4 & 5 & 6 & 7 & 158 & 32 \\
\hline 3 & 2 & 1 & - & 1 & 2 & 3 & 3 & 2 & 3 & 4 & 5 & 4 & 5 & 6 & 7 & 6 & 6 & 7 & 7 & 6 & 5 & 4 & 4 & 3 & 4 & 5 & 6 & 7 & 8 & 9 & 8 & 5 & 6 & 7 & 6 & 167 & 34 \\
\hline 4 & 3 & 2 & 1 & - & 1 & 2 & 2 & 1 & 2 & 3 & 4 & 3 & 4 & 5 & 6 & 5 & 5 & 6 & 6 & 5 & 4 & 3 & 4 & 4 & 5 & 5 & 5 & 6 & 7 & 8 & 7 & 6 & 7 & 8 & 5 & 150 & 28 \\
\hline 5 & 2 & 1 & 2 & 1 & - & 1 & 2 & 2 & 3 & 3 & 4 & 4 & 5 & 6 & 7 & 6 & 5 & 7 & 5 & 4 & 3 & 2 & 3 & 3 & 5 & 4 & 4 & 5 & 6 & 7 & 8 & 5 & 6 & 7 & 6 & 144 & 23 \\
\hline 6 & 3 & 2 & 3 & 2 & 1 & - & 1 & 2 & 3 & 2 & 3 & 4 & 5 & 6 & 7 & 6 & 4 & 6 & 4 & 3 & 2 & 1 & 2 & 3 & 4 & 3 & 3 & 4 & 5 & 6 & 7 & 5 & 5 & 6 & 5 & 128 & 11 \\
\hline 7 & 4 & 3 & 3 & 2 & 2 & 1 & - & 1 & 2 & 1 & 2 & 3 & 4 & 5 & 6 & 5 & 4 & 6 & 4 & 3 & 3 & 2 & 3 & 4 & 5 & 4 & 4 & 5 & 5 & 6 & 7 & 6 & 6 & 7 & 5 & 133 & 17 \\
\hline 8 & 4 & 3 & 2 & 1 & 2 & 2 & 1 & - & 1 & 2 & 3 & 2 & 3 & 4 & 5 & 4 & 4 & 5 & 5 & 4 & 4 & 3 & 4 & 5 & 6 & 5 & 5 & 6 & 6 & 7 & 6 & 7 & 7 & 7 & 4 & 139 & 19 \\
\hline 9 & 5 & 4 & 3 & 2 & 3 & 3 & 2 & 1 & - & 1 & 2 & 1 & 2 & 3 & 4 & 3 & 3 & 4 & 4 & 3 & 4 & 4 & 5 & 6 & 7 & 6 & 5 & 6 & 5 & 6 & 5 & 8 & 7 & 6 & 3 & 136 & 18 \\
\hline 10 & 5 & 4 & 4 & 3 & 3 & 2 & 1 & 2 & 1 & - & 1 & 2 & 3 & 4 & 5 & 4 & 3 & 5 & 3 & 2 & 3 & 3 & 4 & 5 & 6 & 5 & 4 & 5 & 4 & 5 & 6 & 7 & 6 & 7 & 4 & 131 & 15 \\
\hline 11 & 6 & 5 & 5 & 4 & 4 & 3 & 2 & 3 & 2 & 1 & - & 1 & 2 & 3 & 4 & 3 & 2 & 4 & 2 & 1 & 2 & 3 & 4 & 5 & 5 & 4 & 3 & 4 & 3 & 4 & 5 & 6 & 5 & 6 & 3 & 119 & 5 \\
\hline 12 & 6 & 5 & 4 & 3 & 4 & 4 & 3 & 2 & 1 & 2 & 1 & - & 1 & 2 & 3 & 2 & 2 & 3 & 3 & 2 & 3 & 4 & 5 & 6 & 6 & 5 & 4 & 5 & 4 & 5 & 4 & 7 & 6 & 5 & 2 & 124 & 9 \\
\hline 13 & 7 & 6 & 5 & 4 & 5 & 5 & 4 & 3 & 2 & 3 & 2 & 1 & - & 1 & 2 & 1 & 1 & 2 & 2 & 2 & 3 & 4 & 5 & 6 & 6 & 5 & 4 & 4 & 3 & 4 & 3 & 6 & 5 & 4 & 1 & 121 & 8 \\
\hline 14 & 8 & 7 & 6 & 5 & 6 & 6 & 5 & 4 & 3 & 4 & 3 & 2 & 1 & - & 1 & 1 & 2 & 2 & 3 & 3 & 4 & 5 & 6 & 7 & 7 & 6 & 5 & 5 & 4 & 4 & 3 & 6 & 5 & 4 & 2 & 145 & 26 \\
\hline 15 & 9 & 8 & 7 & 6 & 7 & 7 & 6 & 5 & 4 & 5 & 4 & 3 & 2 & 1 & - & 2 & 3 & 3 & 4 & 4 & 5 & 6 & 7 & 8 & 8 & 7 & 6 & 6 & 5 & 5 & 4 & 7 & 6 & 5 & 3 & 178 & 35 \\
\hline 16 & 8 & 7 & 6 & 5 & 6 & 6 & 5 & 4 & 3 & 4 & 3 & 2 & 1 & 1 & 2 & - & 2 & 1 & 3 & 3 & 4 & 5 & 6 & 7 & 6 & 6 & 5 & 5 & 4 & 3 & 2 & 5 & 4 & 3 & 2 & 139 & 22 \\
\hline 17 & 6 & 6 & 6 & 5 & 5 & 4 & 4 & 4 & 3 & 3 & 2 & 2 & 1 & 2 & 3 & 2 & - & 2 & 2 & 1 & 2 & 3 & 4 & 5 & 5 & 4 & 3 & 4 & 3 & 4 & 3 & 6 & 5 & 4 & 1 & 119 & 5 \\
\hline 18 & 7 & 8 & 7 & 6 & 7 & 6 & 6 & 5 & 4 & 5 & 4 & 3 & 2 & 2 & 3 & 1 & 2 & - & 2 & 3 & 4 & 5 & 6 & 6 & 5 & 6 & 5 & 4 & 3 & 2 & 1 & 4 & 3 & 2 & 1 & 140 & 20 \\
\hline 19 & 6 & 6 & 7 & 6 & 5 & 4 & 4 & 5 & 4 & 3 & 2 & 3 & 2 & 3 & 4 & 3 & 2 & 2 & - & 1 & 2 & 3 & 4 & 5 & 5 & 4 & 3 & 2 & 1 & 2 & 3 & 4 & 3 & 4 & 1 & 118 & 4 \\
\hline 20 & 5 & 5 & 6 & 5 & 4 & 3 & 3 & 4 & 3 & 2 & 1 & 2 & 2 & 3 & 4 & 3 & 1 & 3 & 1 & - & 1 & 2 & 3 & 4 & 4 & 3 & 2 & 3 & 2 & 3 & 4 & 5 & 4 & 5 & 2 & 107 & 2 \\
\hline 21 & 4 & 4 & 5 & 4 & 3 & 2 & 3 & 4 & 4 & 3 & 2 & 3 & 3 & 4 & 5 & 4 & 2 & 4 & 2 & 1 & - & 1 & 2 & 3 & 3 & 2 & 1 & 2 & 3 & 4 & 5 & 4 & 3 & 4 & 3 & 106 & 1 \\
\hline 22 & 3 & 3 & 4 & 3 & 2 & 1 & 2 & 3 & 4 & 3 & 3 & 4 & 4 & 5 & 6 & 5 & 3 & 5 & 3 & 2 & 1 & - & 1 & 2 & 3 & 2 & 2 & 3 & 4 & 5 & 6 & 4 & 4 & 5 & 4 & 114 & 3 \\
\hline 23 & 2 & 4 & 5 & 4 & 3 & 2 & 3 & 4 & 5 & 4 & 4 & 5 & 5 & 6 & 7 & 6 & 4 & 6 & 4 & 3 & 2 & 1 & - & 1 & 2 & 1 & 2 & 3 & 4 & 5 & 6 & 3 & 4 & 5 & 5 & 130 & 12 \\
\hline 24 & 1 & 2 & 3 & 4 & 3 & 3 & 4 & 5 & 6 & 5 & 5 & 6 & 6 & 7 & 8 & 7 & 5 & 6 & 5 & 4 & 3 & 2 & 1 & - & 1 & 2 & 3 & 4 & 5 & 6 & 5 & 2 & 3 & 4 & 6 & 142 & 23 \\
\hline 25 & 2 & 3 & 4 & 5 & 5 & 4 & 5 & 6 & 7 & 6 & 5 & 6 & 6 & 7 & 8 & 6 & 5 & 5 & 5 & 4 & 3 & 3 & 2 & 1 & - & 1 & 2 & 3 & 4 & 5 & 4 & 1 & 2 & 3 & 6 & 144 & 24 \\
\hline 26 & 3 & 4 & 5 & 5 & 4 & 3 & 4 & 5 & 6 & 5 & 4 & 5 & 5 & 6 & 7 & 6 & 4 & 6 & 4 & 3 & 2 & 2 & 1 & 2 & 1 & - & 1 & 2 & 3 & 4 & 5 & 2 & 3 & 4 & 5 & 131 & 15 \\
\hline 27 & 4 & 5 & 6 & 5 & 4 & 3 & 4 & 5 & 5 & 4 & 3 & 4 & 4 & 5 & 6 & 5 & 3 & 5 & 3 & 2 & 1 & 2 & 2 & 3 & 2 & 1 & - & 1 & 2 & 3 & 4 & 3 & 2 & 3 & 4 & 118 & 5 \\
\hline 28 & 5 & 6 & 7 & 6 & 5 & 4 & 5 & 6 & 6 & 5 & 4 & 5 & 4 & 5 & 6 & 5 & 4 & 4 & 2 & 3 & 2 & 3 & 3 & 4 & 3 & 2 & 1 & - & 1 & 2 & 3 & 2 & 1 & 2 & 3 & 129 & 12 \\
\hline 29 & 6 & 7 & 8 & 7 & 6 & 5 & 5 & 6 & 5 & 4 & 3 & 4 & 3 & 4 & 5 & 4 & 3 & 3 & 1 & 2 & 3 & 4 & 4 & 5 & 4 & 3 & 2 & 1 & - & 1 & 2 & 3 & 2 & 3 & 2 & 130 & 12 \\
\hline 30 & 7 & 8 & 9 & 7 & 8 & 6 & 6 & 7 & 6 & 5 & 4 & 5 & 4 & 4 & 5 & 3 & 4 & 2 & 2 & 3 & 4 & 5 & 5 & 6 & 5 & 4 & 3 & 2 & 1 & - & 1 & 4 & 3 & 2 & 3 & 153 & 30 \\
\hline 31 & 6 & 7 & 8 & 7 & 8 & 7 & 7 & 6 & 5 & 6 & 5 & 4 & 3 & 3 & 4 & 2 & 3 & 1 & 3 & 4 & 5 & 6 & 6 & 5 & 4 & 5 & 4 & 3 & 2 & 1 & - & 3 & 2 & 1 & 2 & 148 & 27 \\
\hline 32 & 3 & 4 & 5 & 6 & 5 & 5 & 6 & 7 & 8 & 7 & 6 & 7 & 6 & 6 & 7 & 5 & 6 & 4 & 4 & 5 & 4 & 4 & 3 & 2 & 1 & 2 & 3 & 2 & 3 & 4 & 3 & - & 1 & 2 & 5 & 151 & 30 \\
\hline 33 & 4 & 5 & 6 & 7 & 6 & 5 & 6 & 7 & 7 & 6 & 5 & 6 & 5 & 5 & 6 & 4 & 5 & 3 & 3 & 4 & 3 & 4 & 4 & 3 & 2 & 3 & 2 & 1 & 2 & 3 & 2 & 1 & - & 1 & 4 & 140 & 20 \\
\hline 34 & 5 & 6 & 7 & 8 & 7 & 6 & 7 & 7 & 6 & 7 & 6 & 5 & 4 & 4 & 5 & 3 & 4 & 2 & 4 & 5 & 4 & 5 & 5 & 4 & 3 & 4 & 3 & 2 & 3 & 2 & 1 & 2 & 1 & - & 3 & 150 & 28 \\
\hline 35 & 7 & 7 & 6 & 5 & 6 & 5 & 5 & 4 & 3 & 4 & 3 & 2 & 1 & 2 & 3 & 2 & 1 & 1 & 1 & 2 & 3 & 4 & 5 & 6 & 6 & 5 & 4 & 3 & 2 & 3 & 2 & 5 & 4 & 3 & - & 125 & 10 \\
\hline
\end{tabular}

